\title{
Association between anemia, physical performance and cognitive function in Iranian elderly people: evidence from Bushehr Elderly Health (BEH) program
}

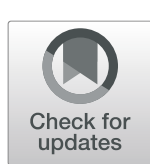

Maryam Marzban ${ }^{1} \mathbb{D}$, Iraj Nabipour ${ }^{2} \mathbb{D}$, Akram Farhadi $^{2,3^{*}}$ (D), Afshin Ostovar ${ }^{4} \mathbb{D}$, Bagher Larijani $^{5}$, Amir Hossein Darabi ${ }^{2}$, Elnaz Shabankari ${ }^{6}$ (D) and Mohamad Gholizade ${ }^{2,3}$ (D)

\begin{abstract}
Background and objectives: The present study aimed to investigate the relation between anemia and hemoglobin ( $\mathrm{Hgb}$ ) concentration, physical performance, and cognitive function in a large sample of Iranian elderly population.

Methods: Data were collected from Bushehr elderly health (BEH) program. A total of 3000 persons aged $\geq 60$ years were selected through multistage random sampling. Hemoglobin values lower than 12 and $13 \mathrm{~g} / \mathrm{dL}$ were considered as anemia for women and men, respectively. The cognitive function was measured using the Mini-cog test and Category fluency test (CFT), and the physical function was measured using handgrip strength (muscle strength), Relative handgrip strength (RHGS), and 4.57-m usual gait speed. Univariate and adjusted multivariate logistic regression and linear regression with Stata MP (version 15) were run, and a $p$-value of $<0.05$ was used as statistically significant for all analyses.

Results: Among participants, 7.43\% were anemic, and 115 (51.57\%) simultaneously had anemia and cognitive disorder. There were significant associations between red blood cell count (RBC), hemoglobin (Hgb), platelet count (PLT), and hematocrit percentage (HCT) with cognitive impairment. Additionally, Hgb concentration was significantly associated with all physical measures (Mean handgrip, Relative handgrip, and usual gait speed) and late recall (mini-cog) among the whole participants. This association remained statistically significant after considering multi-cofounders. In contrast, after stratifying the participants by gender, the association between $\mathrm{Hgb}$ concentration and usual gait speed was decreased in both men and women; moreover, Hgb association with cognitive measures (category fluency test and late recall) was no longer significant (all $p$-values $>0.05$ ).
\end{abstract}

\footnotetext{
* Correspondence: ak.farhadi@gmail.com

${ }^{2}$ The Persian Gulf Tropical Medicine Research Center, The Persian Gulf Biomedical Sciences Research Institute, Bushehr University of Medical Sciences, Bushehr, Iran

${ }^{3}$ The Persian Gulf Marine Biotechnology Research Center, The Persian Gulf Biomedical Sciences Research Institute, Bushehr University of Medical Sciences, Bushehr, Iran

Full list of author information is available at the end of the article
}

(c) The Author(s). 2021 Open Access This article is licensed under a Creative Commons Attribution 4.0 International License, which permits use, sharing, adaptation, distribution and reproduction in any medium or format, as long as you give appropriate credit to the original author(s) and the source, provide a link to the Creative Commons licence, and indicate if changes were made. The images or other third party material in this article are included in the article's Creative Commons licence, unless indicated otherwise in a credit line to the material. If material is not included in the article's Creative Commons licence and your intended use is not permitted by statutory regulation or exceeds the permitted use, you will need to obtain permission directly from the copyright holder. To view a copy of this licence, visit http://creativecommons.org/licenses/by/4.0/ The Creative Commons Public Domain Dedication waiver (http://creativecommons.org/publicdomain/zero/1.0/) applies to the data made available in this article, unless otherwise stated in a credit line to the data. 
Conclusion: There was a cross-sectional and significant association between anemia and functional variables (e.g., Relative and mean handgrip) in Iranian elderly population, whereas Semantic memory, Late recall, and walking were more affected by gender.

Keywords: Hemoglobin, Cognition, Anemia, Elderly, Physical, Walking speed, Handgrip

\section{Background}

Anemia is a considerable global problem which is defined through various criteria in older adults. The most acceptable definition is presented by the World Health Organization (WHO), which is defined as a hemoglobin $(\mathrm{Hgb})$ concentration of lower than $13 \mathrm{~g} / \mathrm{dl}(>13 \mathrm{~g} / \mathrm{dl})$ for men and lower than $12 \mathrm{~g} / \mathrm{dl}(>12 \mathrm{~g} / \mathrm{dl})$ for women [1]. The prevalence of anemia is more than 10 to $24 \%$ in older ages $[2,3]$, which reaches $48 \%$ in hospitalized older individuals [4], and it affects $67 \%$ of senior adults living in a nursing home [5]. Although anemia is not considered a disease entity, it may have some adverse effects on health and could be associated with several clinical complications like reduced muscle strength, physical performance, cognitive impairment, and dementia [6-8].

According to the World Population Prospects, the number of older adults over 65 is expected to rise from 703 million in 2019 to 1.5 billion in 2050 . The growth rate has dramatically increased compared to the previous predictions. The advanced age population also keeps on rising in lower- and middle-income countries such as Iran [9]. Iran is experiencing a rapidly growing rate of the elderly. It is expected that the elderly population will increase from $6.17 \%$ in 2015 to $21.7 \%$ in 2050 [10]. Aging is associated with functional disabilities (physical and cognitive) and age-related diseases, which result in a significant increase in the therapeutic costs and influences in socioeconomic status [9]. Cognitive impairment (CI) is a common complication of aging increasing, especially in developing countries. Studies demonstrate that 50 million people in the world currently have dementia, and it will increase to 131 million by 2050 [11, 12]. The most massive increases are expected in the countries with the highest rates of anemia [11, 13].

Potential cognitive impacts related to inadequate iron might stem from cerebral hypoxia [7, 14], insufficient neurotransmitter synthesis, or low myelin integrity [6]. Based on the results of the studies, the causal relationship between low Hgb and adverse outcomes such as impaired physical and cognitive performance is unclear $[7,8,13,15]$. No trials have confirmed the complete improvement of cognitive and physical function after the treatment of anemia in the elderly [13, 15]. Although some studies have confirmed the significant relationship between Hgb concentration and CI $[6,8]$, others have exhibited no significant association between anemia and CI $[13,16]$.
With the growing number of demented elderly and lack of an effective pharmacological cure for this disease, the most crucial preventive strategy is controlling its modifiable risk factors such as anemia, but this preventive approach is very complicated $[8,12]$. To address the fundamental questions about anemia related to cognitive impairment in older adults and its complex consequences, it will be critical for ensuring commensurate research, clinical, and public health responses to anemia. Therefore, the present study aims to investigate the relation between $\mathrm{Hgb}$ concentration, physical performance, and cognitive function in the elderly.

\section{Methods and measurements \\ Participants and data sources}

The BEH Program is a population-based, prospective cohort study currently being conducted in Bushehr, Iran. The target population of this study was all men and women aged 60 years and over living in Bushehr, the center of a southern province of Iran in the north of the Persian Gulf. The methodology of the BEH program has been previously described elsewhere $[17,18]$. A total of 3000 persons aged $\geq 60$ years were selected through a multistage, stratified cluster random sampling method from an estimated population of about 10,000 individuals (Based on Bushehr health center information). The number of participants was proportional to the number of households residing in each of the 75 strata of $\mathrm{Bu}-$ shehr port, Iran. Baseline measurements of the first stage were implemented from March 2013 to October 2014. The second stage began in October 2015, and data was recollected for 2 years. The inclusion criteria were as follows: age more than or equal to 60 years, comprising both sexes (males and females), residency in Bushehr port since at least 1year before the recruitment and having no plan to leave the city for the next 2 years, adequate physical and mental ability to participate in the evaluation program and signing a written informed consent. From among 3297 participants who met the inclusion criteria, 3000 participants (1455 men and 1545 women) accepted to be involved (participation rate: $91.0 \%$ ). Of those 3000 people who participated in the first phase, 2426 people remained in the second phase of the study ( $80 \%$ response rate), and 574 people were excluded due to death, migration, or unwillingness to participate in the study. They were checked by a trained nurse once a year for the outcomes, and a form was 
given to the participants for self-reporting at the earliest opportunity after the incident of any of the marked outcomes. All participants were asked to fill validated questionnaires that were translated into Persian. All Bushehr Elderly Health program participants provided written informed consent, and the Research Ethics Committee approved the study protocol of Bushehr University of Medical Sciences (Reference number: B-91-14-2).

\section{Laboratory examinations}

All participants were asked to provide $10 \mathrm{~mL}$ of the whole blood taken by a trained nurse after $8-12 \mathrm{~h}$ of fasting for laboratory tests. The whole blood included complete blood count (CBC), Mean corpuscular volume (MCV), Red blood cell count (RBC), Hgb, White blood cells (WBC), Platelets (PLT), Red Cell Distribution Width (RDW), Mean corpuscular hemoglobin $(\mathrm{MCH})$, Fasting blood sugar and lipid profile. The automated hematology analyzer, Medonic CA620 (Menarini Diagnostic Srl, Florence, Italy), was used for the measurements.

According to the World Health Organization criteria, anemia is defined as Hgb concentrations lower than 13 $\mathrm{g} / \mathrm{dl}$ for men and lower than $12 \mathrm{~g} / \mathrm{dl}$ for women [1].. Thus, the anemic cases were categorized by mean corpuscular volume (MCV) and Hgb concentration. Microcytic anemia was defined as MCV lower than 80 femtolitre MCV < 80, and normocytic anemia MCV 80 to 100 femtolitre and macrocyte anemia were define as MCV > 100 femtolitres [9].

\section{Measures of cognitive function}

Evaluation of cognitive function started in the second phase of the study. Mini-cog and category fluency test (CFT) were used for evaluating the cognitive function, which have already been validated and translated for use in primary care in Iran [19]. Men and women who had a low score in one or more tests were considered cognitively impaired.

Mini-Cog is a validated and brief screening test for measuring $\mathrm{CI}$ that takes approximately $3 \mathrm{~min}$ to perform and consists of two parts; the first part assesses the participant's ability to recall three words. Individuals who could recall all three words are considered to have normal cognition abilities and others as cognitively impaired. For those who could only recall one or two words, a clock-drawing test is performed. Those who could correctly draw the clock are assumed to have a normal cognitive function and others to have an impaired cognitive function [17]. This test has the least language content; therefore, lower cultural and educational bias is found in this test [20].

Categorical verbal fluency test (CFT): It is a short screening test that evaluates cognitive function (semantic memory). This CFT requires the participant to name as many examples of the category "animal" as possible within $1 \mathrm{~min}$. A previous report has shown that a cut-off score of $13 / 14$ on the CFT was able to distinguish patients with $\mathrm{AD}$ from control subjects with a sensitivity of 0.91 and a specificity of 0.81 [21].

\section{Measures of physical function}

To test physical function, handgrip strength (muscle strength), Relative Handgrip Strength (RHGS) [22], and 4.57-m usual gait speed (physical performance) were measured. The intensity of the physical activity level in $24 \mathrm{~h}$ of work, sports, and leisure time was expressed in metabolic equivalents. Four categories were defined based on the level of physical activity (sedentary: 1-1.39, low active: $1.4-1.59$, active: $1.6-1.89$, very active: $1.9-$ 2.5) [23]. This instrument is a valid self-report questionnaire that has been validated among Iranian adolescents for Farsi language [23, 24].

\section{Relative handgrip strength (RHGS)}

Recently, using BMI to adjust for handgrip strength has been recommended as a muscle quality index [22]. Thus, we used RHGS instead of absolute handgrip strength, defined as the average value for maximum grip strength of the dominant hand divided by BMI, which was calculated as weight divided by height squared $\left(\mathrm{kg} / \mathrm{m}^{2}\right)$ [25].

\section{Covariates}

Covariates included age, sex, marital status (single, married, divorced, widow), body mass index, physical activity (not active, sedentary, low active, active, very active), depression (defined as self-reported physician diagnosis, medication use), Alzheimer's (defined as self-reported and medication use) and Parkinson's (defined as selfreported and medication use). Diabetes was defined as $\mathrm{HbA} 1 \mathrm{C} \geq 6.5$, and $\mathrm{HbA} 1 \mathrm{C}$ level was used to assess whether the diabetes is controlled [26-28].

Hypertension (defined as medication use, systolic blood pressure $\geq 140 \mathrm{mmHg}$, or diastolic blood pressure $\geq 90 \mathrm{mmHg}$ ), current, past smoking (Yes regularly, Yes Occasionally, No), and Glomerular filtration rate (GFR) was calculated by standard formulae.

Each participant's height was measured using a stadiometer, with a precision of $1 \mathrm{~cm}$. The participant's weight was measured while wearing light clothing and no shoes, using scales with a precision of $100 \mathrm{~g}$. The body mass index (BMI) was defined as the weight in kilograms divided by height in meters squared (weight $(\mathrm{kg}) /\left[\right.$ height $(\mathrm{m})^{2}$ ).

\section{Statistical analysis}

The normal distribution of the data was checked. The general characteristics of the participants were evaluated 
for anemic and non-anemic groups. For categorical and continuous data $\mathrm{x}^{2}$, and t-test were used, respectively. The relationship between cognitive impairment and hematological parameters was evaluated by logistic regression. Besides this, the linear regression analyses were used to investigate the relationship between physical performances, including mean handgrip strength (muscle strength), Relative Handgrip Strength (RHGS), and $4.57-\mathrm{m}$ usual gait speed, and cognitive function included category fluency test, and late recall with hemoglobin level. Covariates that have a significant clinical and pathophysiological association with desired outcomes of this study (e.g., age, sex, marital status, body mass index, physical activity, depression, diabetes, hypertension, smoking, Alzheimer \& Parkinson disease, and GFR) were first assessed by univariate regression models. Covariates that were statistically significant were used in multivariate regression analyses. Then they were used as four regression models to adjust the relationship between hemoglobin, physical performance, and cognitive function. In the first model (model 1), the relationship between anemia, physical performance, and cognitive
Function was adjusted with age. in model 2, this relationship was adjusted with age and education level. In the third statistical model (model 3), the adjustment was with age, education level, marital status, BMI, smoking status. In the last statistical model (model 4), HTN, HbA1c, GFR, Alzheimer's, and Parkinson's were added to the model 3. Stata MP (version 15) was used, and a $p$ value of $<0.05$ was taken as statistically significant for all analyses.

\section{Results}

Of 2426 participants, 1260 (51.94\%) were female. The mean age was $69.34 \pm 6.39$ years. Two hundred twentythree of the participants (7.43\%) were anemic (Table 1). Among participants with anemia, 197 (88.34\%) had normocytic anemia (Table 2).

Table 1 shows the sample characteristics between the anemic and non-anemic groups. For both genders, there was a significant difference between anemic and nonanemic participants in age, marital status, mean BMI, and mean Hgb concentration. Among men, BMI was significantly lower in the anemic group, but not in

Table 1 Characteristics of the participants by anemia status; BEH program $(n=2426)$

\begin{tabular}{|c|c|c|c|c|c|}
\hline Variable & & Total (2426) & Anemic (223) & Non-anemic (2777) & $P$-value \\
\hline Mean age (years) & & $69.34 \pm 6.39$ & $69.16 \pm 6.25$ & $71.07 \pm 7.43$ & $<0.0001$ \\
\hline Female sex (\%) & & $1545(51.50)$ & $108(48.43)$ & $1340(48.25)$ & 0.340 \\
\hline \multirow[t]{4}{*}{ Marital status, n (\%) } & Single & $25(0.83)$ & - & $25(0.90)$ & \\
\hline & Married & $2248(74.93)$ & $167(74.89)$ & $2081(74.94)$ & \\
\hline & Divorce & $26(0.87)$ & $3(1.35)$ & $23(0.83)$ & \\
\hline & Widow & $701(23.37)$ & $53(23.77)$ & $648(23.33)$ & \\
\hline \multirow[t]{2}{*}{ Mean hemoglobin concentration (g/dl) (SD) } & Males & $15.06 \pm 1.73$ & $11.89 \pm 0.95$ & $15.41 \pm 1.42$ & 0.0001 \\
\hline & Females & $13.96 \pm 1.56$ & $11.14 \pm 0.87$ & $14.22 \pm 1.33$ & 0.0001 \\
\hline \multirow[t]{2}{*}{ Mean BMI $\left(\mathrm{kg} / \mathrm{m}^{2}\right)$} & Males & $25.20 \pm 4.01$ & $25.20 \pm 4.01$ & $26.35 \pm 4.00$ & 0.003 \\
\hline & Females & $28.70 \pm 5.33$ & $28.26 \pm 6.10$ & $28.74 \pm 5.26$ & 0.365 \\
\hline Mean hand grip & & $22.16 \pm 9.23$ & $19.88 \pm 8.19$ & $22.39 \pm 9.29$ & 0.0001 \\
\hline Walking $4.57 \mathrm{~m} / \mathrm{s}$ & & $6.68 \pm 5.75$ & $7.15 \pm 4.03$ & $6.64 \pm 5.89$ & 0.203 \\
\hline Positive for Hypertension & & $1818(75.16)$ & $178(79.82)$ & $1640(74.68)$ & 0.170 \\
\hline Positive for Diabetes & & $1228(50.68)$ & $118(52.91)$ & $1110(50.45)$ & 0.713 \\
\hline Positive Cognitive disorder, n (\%) & & $1194(39.80)$ & $115(51.57)$ & $1079(38.85)$ & 0.0001 \\
\hline \multirow[t]{3}{*}{ Smoking } & None & 735 (30.32) & $84(37.67)$ & $651(29.58)$ & 0.021 \\
\hline & Past cigarette or hookah & $1185(48.89)$ & $104(46.64)$ & $1081(49.11)$ & \\
\hline & current cigarette or hookah & $504(20.79)$ & $35(15.70)$ & $469(21.31)$ & \\
\hline \multirow[t]{5}{*}{ Physical activity, n (\%) } & Not active & $155(6.39)$ & $25(11.21)$ & $130(5.91)$ & 0.001 \\
\hline & Sedentary & $1714(70.71)$ & $164(73.54)$ & $1550(70.42)$ & \\
\hline & Low active & $397(16.38)$ & $22(9.87)$ & $375(17.04)$ & \\
\hline & Active & $132(5.45)$ & $8(3.59)$ & $124(5.63)$ & \\
\hline & Very active & $26(1.07)$ & $4(1.79)$ & $22(1.00)$ & \\
\hline
\end{tabular}

For categorical and continuous data $\mathrm{x}^{2}$, and $\mathrm{t}$-test were used respectively $B E H$ Program Bushehr Elderly Health Program, BMI The body mass index 
Table 2 The types of anemia in the BEH program

\begin{tabular}{llll}
\hline Types of anemia & Anemia & & Moderate to severe \\
\cline { 2 - 4 } & Mild & $2(0.90)$ & Total \\
\hline Microcyte anemia, $\mathbf{n}(\%)$ & $19(8.52)$ & $8(3.59)$ & $197(88.34)$ \\
Normocyte anemia, $\mathbf{n}(\%)$ & $\mathbf{1 8 9 ( 8 4 . 7 5 )}$ & $0(0.00)$ & $5(2.24)$ \\
Macrocyte anemia, $\mathbf{n}(\%)$ & $5(2.24)$ & $10(4.48)$ & $223(100)$ \\
\hline
\end{tabular}

Notes: Microcyte Anemia was defined as MCV lower than 80 femtolitres (MCV < 80) and normocyte anemia (MCV 80 to 100$)$ femtolitre and macrocyte anemia were define as (MCV > 100) femtolitre

Anemic cases were divided into severe and mild anemia. Mild anemia is defined as HGB $(\mathrm{Hb})$ concentration between 10 to $12 \mathrm{~g} / \mathrm{dl}$ in women and 10 to $13 \mathrm{~g} / \mathrm{dl}$ in men. Moderate to severe was determined as $\mathrm{Hgb}$ concentration lower than $10 \mathrm{~g} / \mathrm{dl}$ in both sexes

women. There was a significant difference in physical activity between the non-anemic and anemic groups $(P=$ 0.001). Compared to non-anemic participants, those with anemia were more sedentary and not-active; they also had a significantly lower mean handgrip $(P=$ 0.0001). Besides, the prevalence of cognitive disorder was significantly higher among anemic participants $(51.57 \%)$ than those without anemia $(38.58 \%) \quad(p=$ $0.0001)$.

The associations of hematological parameters with cognition are shown in Table 3. RBC, mean Hgb, and HCT were significantly lower in the participants with cognitive impairment and had preventive effect from cognitive impairment. [OR $(95 \% \mathrm{CI})=0.7(0.65$ to 0.89$)$, $P$-value $=0.0001$ for $\mathrm{RBC}$; OR $(95 \% \mathrm{CI})=0.94(0.89$ to $0.98), P$-value $=0.009$ for $\mathrm{Hgb}$; OR $(95 \% \mathrm{CI})=0.96(0.95$ to 0.98$), P$-value $=0.0001$ for HCT] .

According to the results of linear regression shown in Table 4, Hgb concentration was positively associated with the category fluency test, late recall, mean handgrip, relative handgrip, while $\mathrm{Hgb}$ concentration had a reverse association with the usual gate speed. After adjustment for education, the association between Hgb concentration and category fluency test

Table 3 The relationship between cognitive impairment and hematological parameters in the BEH Program $(n=2426)$

\begin{tabular}{llllll}
\hline Variable & \multicolumn{2}{l}{ Cognitive disorder } & \multicolumn{2}{l}{ OR [95\% Cl] } & \multicolumn{1}{c}{$\boldsymbol{P}$-value } \\
\cline { 2 - 3 } & Positive & Negative & & \\
\hline RBC & $4.96 \pm 0.66$ & $5.06 \pm 0.61$ & $0.7(0.65$ to 0.89) & $\mathbf{0 . 0 0 0 1}$ \\
WBC & $7.35 \pm 1.82$ & $7.39 \pm 2.49$ & $0.99(0.95$ to 1.02$)$ & 0.637 \\
MCV & $85.78 \pm 8.44$ & $85.67 \pm 8.14$ & $1.00(0.99$ to 1.01$)$ & 0.747 \\
MCH & $29.73 \pm 3.40$ & $29.88 \pm 9.09$ & $0.99(0.9$ to 1.00$)$ & 0.56 \\
RDW & $16.05 \pm 54.73$ & $14.38 \pm 3.62$ & $1.01(0.98$ to 1.04$)$ & 0.445 \\
RDWa & $75.68 \pm 23.14$ & $74.90 \pm 20.32$ & $1.00(0.99$ to 1.00$)$ & 0.401 \\
Hgb & $14.4 \pm 1.82$ & $14.58 \pm 1.65$ & $0.94(0.89$ to 0.98) & $\mathbf{0 . 0 0 9}$ \\
HCT & $42.45 \pm 5.06$ & $43.19 \pm 4.69$ & $0.96(0.95$ to 0.98) & $\mathbf{0 . 0 0 0 1}$ \\
\hline
\end{tabular}

The logistic regression was used for analysis BEH Program Bushehr Elderly Health Program, CBC complete blood count, $\mathrm{Hgb}$ hemoglobin, MCH Mean corpuscular hemoglobin, MCV Mean corpuscular volume, PLT Platelets, RBC Red blood cell count, RDW Red Cell Distribution Width, WBC White blood cells was no longer significant $[\beta(95 \% \mathrm{CI})=0.09(-0.01$ to $0.19), P=0.081]$. In contrast, the association between $\mathrm{Hgb}$ concentration, the late recall test, mean handgrip, relative handgrip, and usual gate speed was significant even after education, and other confounders were considered (model 4$)[\beta(95 \% \mathrm{CI})=0.03$ (0.00 to 0.05$), P=0.010$ for late recall test; $\beta$ $(95 \% \mathrm{CI})=1.30 \quad(1.11$ to 1.48$), P=0.0001$ for mean handgrip; $\beta(95 \% \mathrm{CI})=0.04$ (0.03 to 0.05$), P=0.0001$ for relative handgrip; $\beta(95 \% \mathrm{CI})=-0.12(-0.22$ to $0.01), P=0.020$ for usual gate speed]. After stratifying the participants by gender, the association between $\mathrm{Hgb}$ concentration, Category fluency test, and late recall was no longer significant (all $p$-value $>0.05$ ). Alternatively, when gender was considered separately, the Hgb concentration association with usual gate speed was decreased significantly in both men and women. As shown in Figs. 1 and 2, age was inversely associated with the mean handgrip and relative handgrip in both men and women, which were more potent in men. These results indicated that $\mathrm{Hgb}$ concentration was significantly associated with the mean handgrip and relative handgrip, while usual handgrip, late recall, and Category fluency test (semantic memory) were more affected by gender. Moreover, Figs. 3, 4, and 5 show the relationship between $\mathrm{Hgb}$ concentration, CFT, walking speed, and mean handgrip separately for men and women.

\section{Discussion}

In the present study, we found a significant relationship between anemia and physical function variables such as mean handgrip, relative handgrip, and walking speed. Furthermore, there was an association between anemia and cognitive function variables such as semantic memory and late recall after adjusting for different demographic and clinical variables. We found an association between anemia and walking speed only among men in gender-stratified analyses. Besides, we did not find an association between anemia and cognitive function in gender-stratified evaluations. 
Table 4 Gender-stratified relationship between cognitive \&physical measures and anemia; BEH program $(n=2426)$

\begin{tabular}{|c|c|c|c|c|c|c|c|}
\hline \multirow[t]{2}{*}{ Outcome variable } & \multirow{2}{*}{$\begin{array}{l}\text { Analytic } \\
\text { model }\end{array}$} & \multicolumn{2}{|l|}{ All } & \multicolumn{2}{|l|}{ Male } & \multicolumn{2}{|l|}{ Female } \\
\hline & & $\beta(95 \% \mathrm{Cl})$ & $P$-value & $\beta(95 \% \mathrm{Cl})$ & $P$-value & $\beta(95 \% \mathrm{Cl})$ & $P$-value \\
\hline \multicolumn{8}{|l|}{ Hemoglobin $^{a}$} \\
\hline \multirow{5}{*}{$\begin{array}{l}\text { Category fluency test (semantic } \\
\text { memory) }\end{array}$} & Crude & 0.20 (0.09 to 0.32 ) & 0.0001 & $-0.02(-0.19$ to 0.14$)$ & 0.781 & $0.03(-0.13$ to 0.19$)$ & 0.725 \\
\hline & Model 1 & $0.14(0.02$ to 0.25$)$ & 0.014 & $-0.12(-0.29$ to 0.04$)$ & 0.148 & $\begin{array}{l}-0.03(-0.19 \text { to } \\
0.12)\end{array}$ & 0.681 \\
\hline & Model 2 & $0.09(-0.01$ to 0.19$)$ & 0.081 & $0.00(-0.15$ to 0.16$)$ & 0.922 & $0.07(-0.07$ to 0.22$)$ & 0.343 \\
\hline & Model 3 & $0.06(-0.04$ to 0.17$)$ & 0.251 & $-0.01(-0.17$ to 0.14$)$ & 0.838 & $0.05(-0.09$ to 0.20$)$ & 0.481 \\
\hline & Model 4 & $0.05(-0.05$ to 0.16$)$ & 0.342 & $-0.07(-0.23$ to 0.08$)$ & 0.365 & $0.01(-0.13$ to 0.17$)$ & 0.809 \\
\hline \multirow[t]{5}{*}{ Late recall } & Crude & 0.02 (0.00 to 0.04$)$ & 0.028 & $0.02(-0.00$ to 0.06$)$ & 0.140 & $0.02(-0.00$ to 0.06$)$ & 0.112 \\
\hline & Model 1 & 0.03 (0.01 to 0.05 ) & 0.003 & 0.03 (0.00 to 0.07 ) & 0.029 & 0.03 (0.00 to 0.07 ) & 0.038 \\
\hline & Model 2 & 0.03 (0.01 to 0.05 ) & 0.003 & $0.02(-0.01$ to 0.05$)$ & 0.198 & $0.02(-0.00$ to 0.06$)$ & 0.154 \\
\hline & Model 3 & 0.03 (0.00 to 0.05 ) & 0.011 & $0.02(-0.01$ to 0.05$)$ & 0.169 & $0.03(-0.00$ to 0.06$)$ & 0.094 \\
\hline & Model 4 & 0.03 (0.00 to 0.05$)$ & 0.010 & $0.02(-0.01$ to 0.05$)$ & 0.185 & $0.03(-0.00$ to 0.06$)$ & 0.080 \\
\hline \multirow[t]{5}{*}{ Mean hand grip } & Crude & 1.69 (1.49 to 1.89$)$ & 0.0001 & 0.80 (0.53 to 1.07$)$ & 0.0001 & 0.36 (0.18 to 0.53$)$ & 0.0001 \\
\hline & Model 1 & 1.56 (1.36 to 1.75$)$ & 0.0001 & 0.52 (0.28 to 0.76$)$ & 0.0001 & 0.25 (0.09 to 0.42 ) & 0.002 \\
\hline & Model 2 & 1.50 (1.32to1.68) & 0.0001 & 0.84 (0.58 to 1.10$)$ & 0.0001 & 0.38 (0.21 to 0.56$)$ & 0.0001 \\
\hline & Model 3 & 1.30 (1.11 to 1.48$)$ & 0.0001 & 0.78 (0.52 to 1.04$)$ & 0.0001 & 0.35 (0.17 to0.52) & 0.0001 \\
\hline & Model 4 & 1.30 (1.11 to 1.48$)$ & 0.0001 & 0.57 (90.31 to 0.83 ) & 0.0001 & 0.23 (0.06 to 0.40 ) & 0.006 \\
\hline \multirow[t]{5}{*}{ Relative hand grip } & Crude & 0.06 (0.05 to 0.07 ) & 0.0001 & 0.02 (0.01 to 0.03 ) & 0.0001 & 0.01 (0.00 to 0.01 ) & 0.001 \\
\hline & Model 1 & 0.06 (0.05 to 0.06$)$ & 0.0001 & 0.01 (0.00 to 0.02 ) & 0.019 & 0.00 (0.00 to 0.01$)$ & 0.011 \\
\hline & Model 2 & 0.05 (0.04 to0.06) & 0.0001 & 0.02 (0.01 to 0.03 ) & 0.0001 & 0.01 (0.00 to 0.01 ) & 0.0001 \\
\hline & Model 3 & 0.04 (0.03 to 0.05 ) & 0.0001 & 0.01 (0.00 to 0.01 ) & 0.0001 & 0.01 (0.00 to 0.01 ) & 0.0001 \\
\hline & Model 4 & 0.04 (0.03 to 0.05 ) & 0.0001 & 0.01 (0.00 to 0.02 ) & 0.0001 & 0.00 (0.00 to 0.01$)$ & 0.004 \\
\hline \multirow[t]{5}{*}{ Walking $4.57 \mathrm{~m} / \mathrm{s}$} & Crude & $\begin{array}{l}-0.33(-0.46 \text { to }- \\
0.19)\end{array}$ & 0.0001 & $\begin{array}{l}-0.14(-0.25 \text { to }- \\
0.03)\end{array}$ & 0.010 & $\begin{array}{l}-0.17(-0.43 \text { to } \\
0.08)\end{array}$ & 0.178 \\
\hline & Model 1 & $\begin{array}{l}-0.24(-0.36 \text { to }- \\
0.11)\end{array}$ & 0.0001 & $-0.06(-0.17$ to 0.03$)$ & 0.021 & $\begin{array}{l}-0.05(-0.29 \text { to } \\
0.19)\end{array}$ & 0.686 \\
\hline & Model 2 & $-0.28(-0.41$ to- -0.14$)$ & 0.0001 & $\begin{array}{l}-0.15(-0.26 \text { to }- \\
0.04)\end{array}$ & 0.007 & $\begin{array}{l}-0.20(-0.45 \text { to } \\
0.05)\end{array}$ & 0.118 \\
\hline & Model 3 & $-0.20(-0.34$ to -0.07$)$ & 0.002 & $\begin{array}{l}-0.14(-0.25 \text { to }- \\
0.03)\end{array}$ & 0.013 & $\begin{array}{l}-0.14(-0.40 \text { to } \\
0.11)\end{array}$ & 0.285 \\
\hline & Model 4 & $\begin{array}{l}-0.12(-0.22 \text { to }- \\
0.01)\end{array}$ & 0.020 & $-0.04(-0.16$ to 0.06$)$ & 0.376 & $0.04(-0.13$ to 0.22$)$ & 0.589 \\
\hline
\end{tabular}

The linear regression was used for analysis

a Hemoglobin concentration was used as an independent variable

Model 1 adjusted for age

Model 2 adjusted for education

Model 3 adjusted for age, education level, marital status, BMI, smoking status

Model 4 adjusted for age, education level, marital status, BMI, smoking status, HTN, HbA1c, GFR,Alzehimer's, Parkinson's

Our analyses indicated that approximately $7.43 \%$ of the participants were anemic. Various studies estimated the prevalence of anemia in the elderly, with different conditions and characteristics. Anemia prevalence was $19 \%$ in the Iranian elderly study in Amir Cola [29].14.6\% of older adults had anemia in an Australian epidemiologic study [30]. Moreover, in a systematic review, including 34 studies, the prevalence of anemia was reported $17 \%$ [31]. The contrast in the prevalence of anemia might be due to the diagnostic criteria for anemia, heterogeneity of participants in the race, living conditions, and health problems. Besides, the lower average age of the participants and the higher prevalence of smokers may also contribute to the difference between anemia prevalence in our study with others. The result of our study was consistent with previous cross-sectional and longitudinal studies, which exhibited the prevalence of anemia increased with advancing age [5, 29, 31, 32]. An increase in Hgb concentration in smokers could be caused by carbon monoxide exposure, which is more 


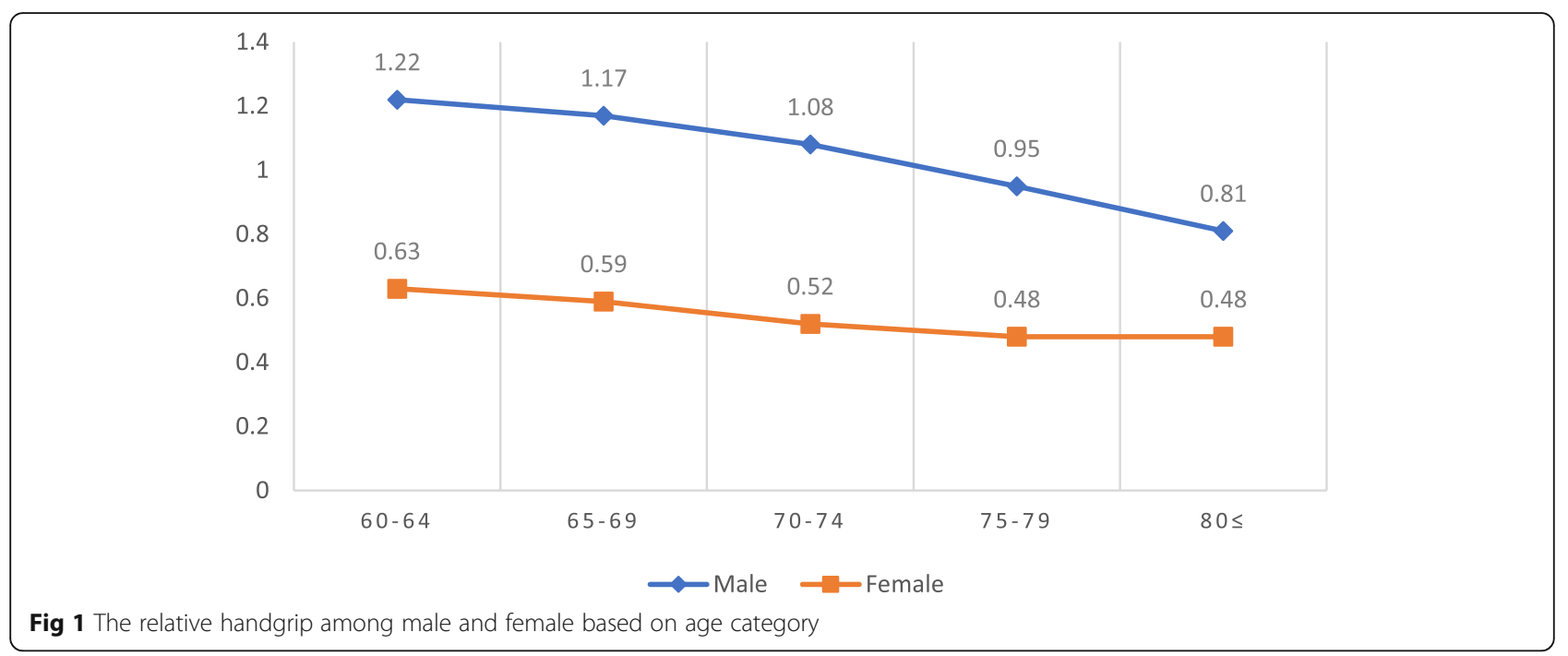

likely to reduce the prevalence of anemia among smokers. Some studies investigated that increasing $\mathrm{Hgb}$ levels in smokers might be a compensatory mechanism. Carbon monoxide $(\mathrm{CO})$ binds to hemoglobin with greater affinity than oxygen. After smoking, carbon-monoxidehemoglobin causes the kidney to detect less oxygen, hypoxia, thus producing more erythrocytes. It affects hemoglobin levels [33]. Therefore, smokers have higher Hgb levels than non-smokers, which is more likely to reduce the prevalence of anemia among smokers. According to previous studies, Hookah smoke is more harmful than cigarettes for passive smokers [34]. It causes an increase in Hgb concentration. The elderly in this study prefer to smoke hookah due to their culture. Therefore, higher Hgb levels in this group are acceptable.

In this study, the most common type of anemia was normocytic. The advanced aged often suffer from chronic diseases, which explains the high prevalence of normocytic anemia in the elderly. This finding was similar to previous studies about the elderly [32].

There was a significant association between hemoglobin levels, RHGS, and handgrip. The association was still substantial and significant after adjusting for potential confounders and considering gender separately. Other studies such as Yu-mi Gi et al. (2020) in Korea [35] and Santos et al. (2018) in Brazil [36] have confirmed a significant relationship between hand-grip and anemia. The mechanisms for the association between $\mathrm{Hgb}$ concentration and muscle strength decline are not fully understood. Hgb plays an essential role in the oxygenation of the muscle tissue. As a result, anemia is associated with a decrease in muscle strength. Anemia decreases the oxygen-carrying capacity, resulting in tissue hypoxia and leads to poor outcomes such as failing muscle strength.

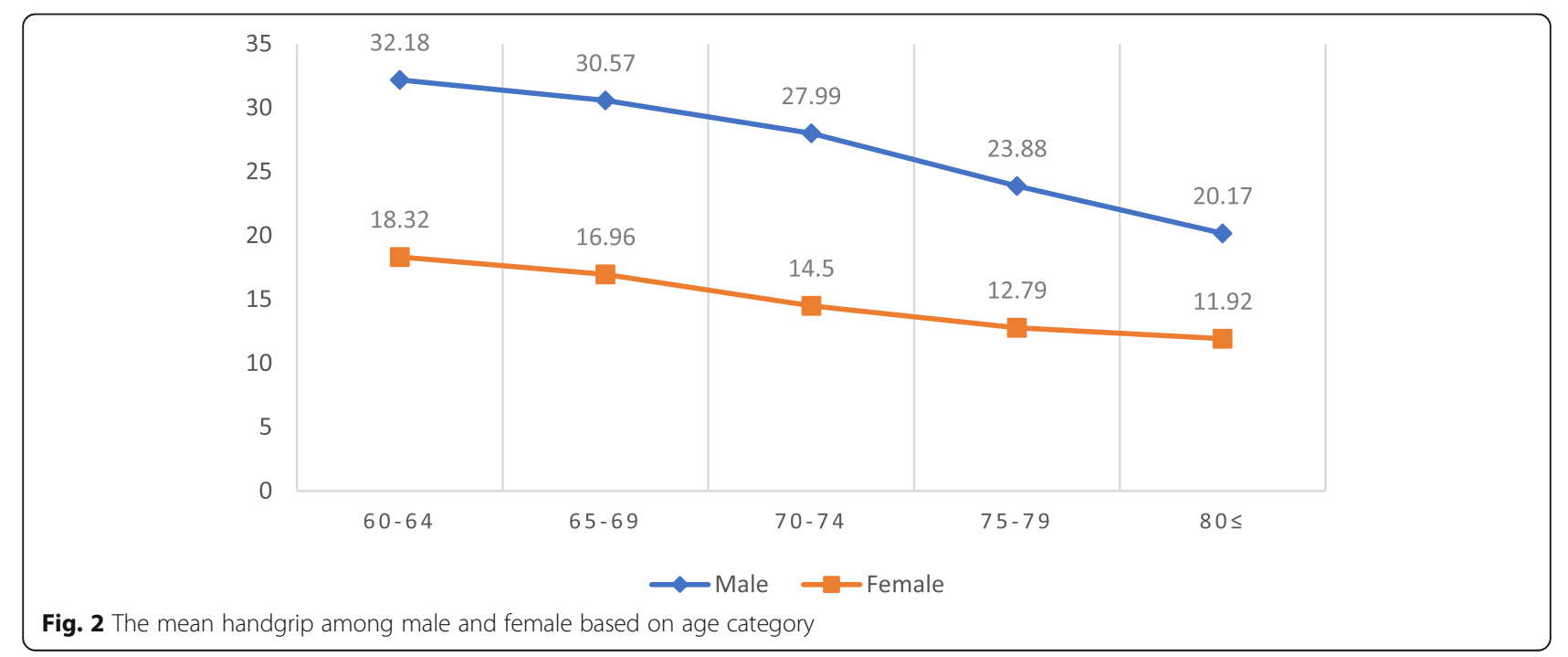




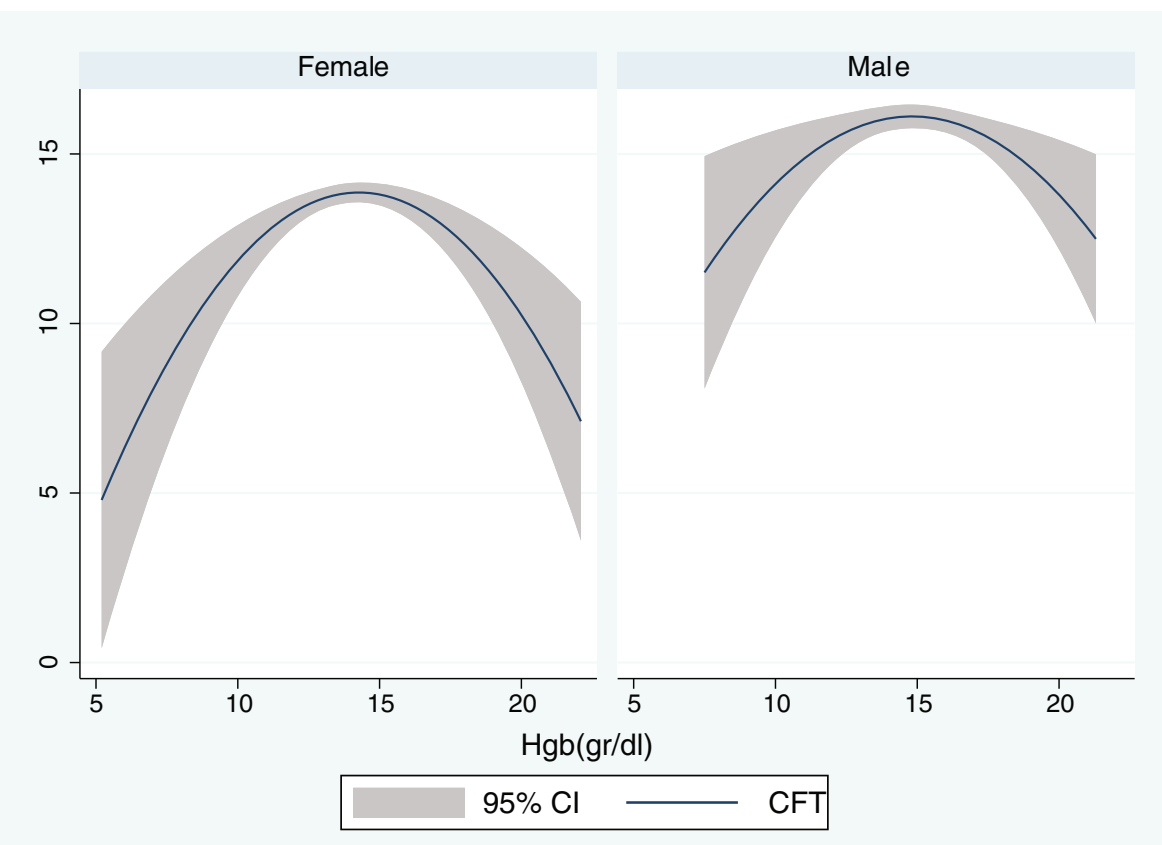

Fig. 3 Fractional polynomial plot and $95 \% \mathrm{Cl}$ association between HGB and CFT

There are some compensatory mechanisms such as dilation of peripheral arteries, activation of the sympathetic angiotensin, and renin aldosterone systems, which cause to maintain blood pressure.

A long-term increase in cardiac output causes left ventricular hypertrophy. That might lead to cardiovascular disease, especially congestive heart failure, which is one of the most common causes of disability [35].

In older individuals, various tissue functions are decreased due to frailty, aging, and chronic diseases. Therefore, anemia might cause tachypnea, tachycardia, decreased exercise tolerance, muscle mass loss, and

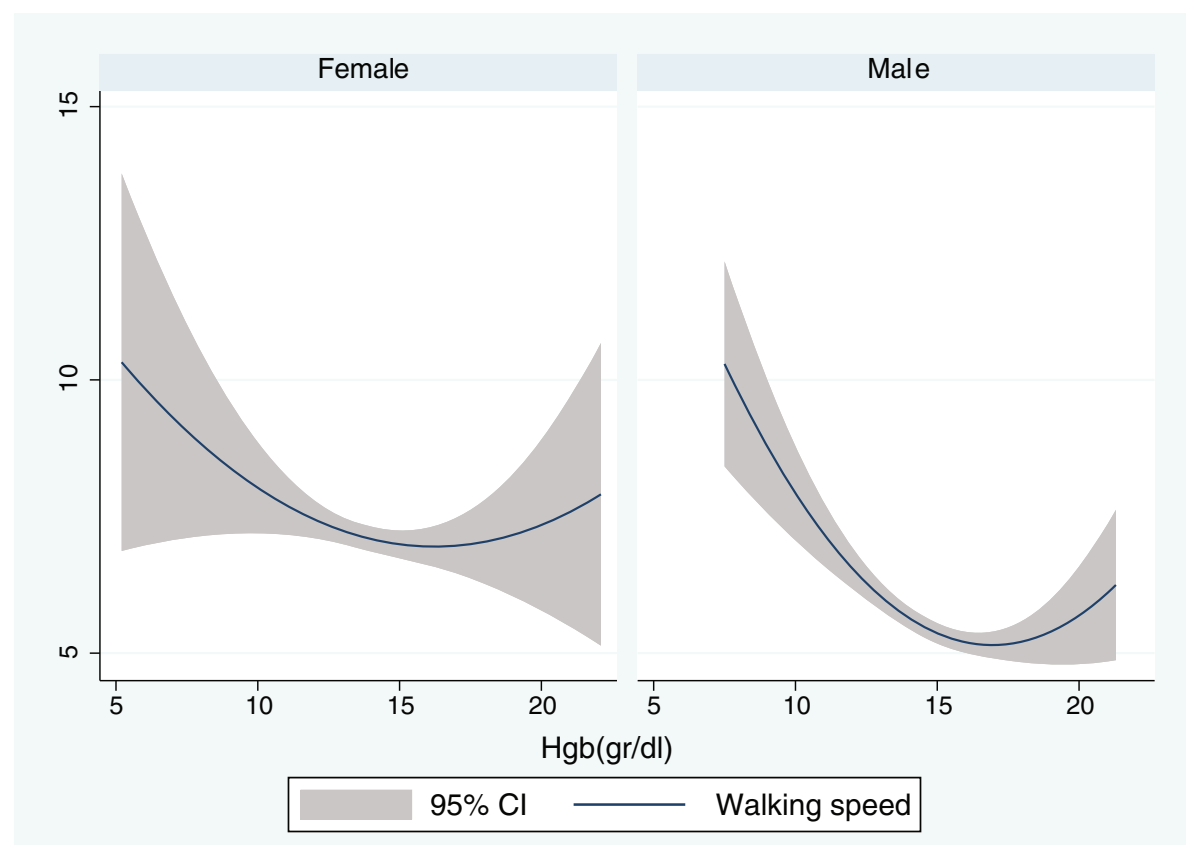

Fig. 4 Fractional polynomial plot and 95\% $\mathrm{Cl}$ association between $\mathrm{HGB}$ and walking speed 


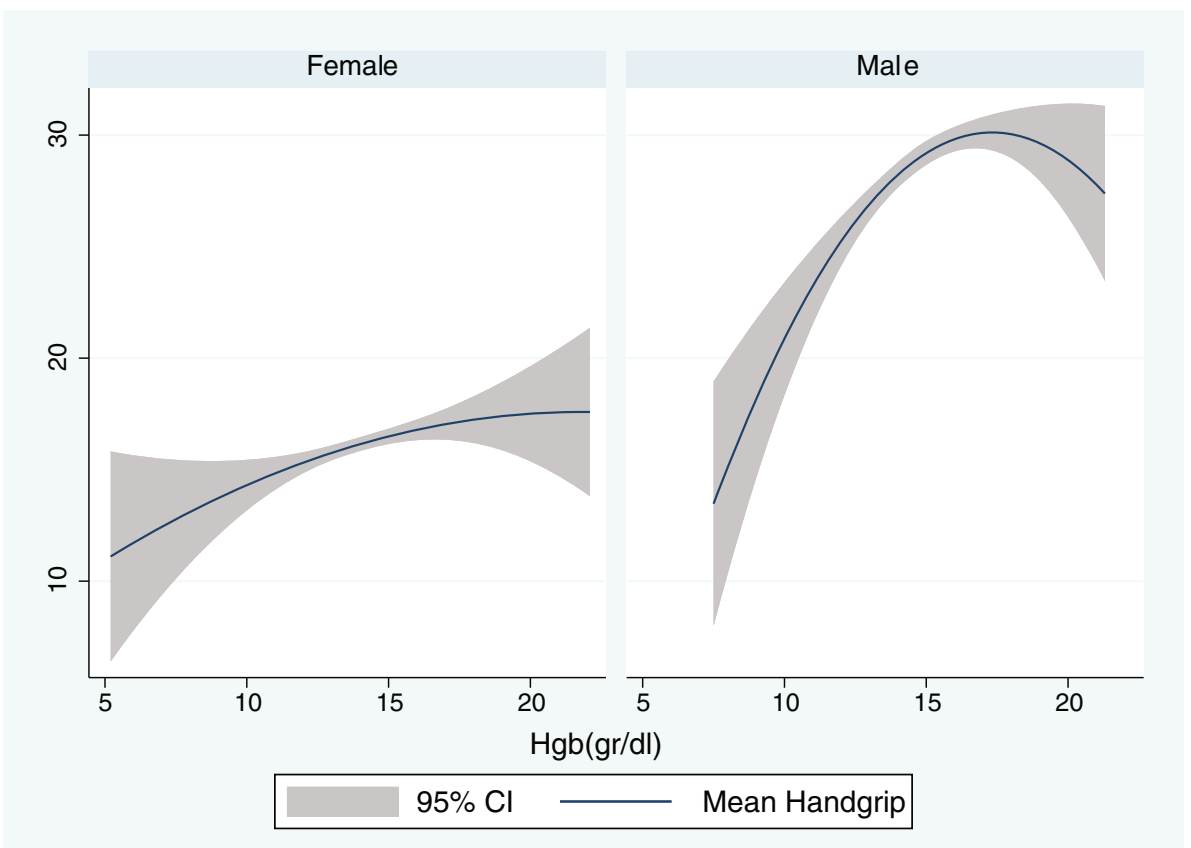

Fig. 5 Fractional polynomial plot and $95 \% \mathrm{Cl}$ association between $\mathrm{HGB}$ and mean hand grip

decreased physical performance. According to some studies, anemia may share a pathophysiological pathway with chronic inflammatory processes that might explain the relationship between anemia and physical function deterioration [35, 37]. In contrast to our research, Joosten et al. (2016) [38] found no association between anemia and physical performance variables such as handgrip and usual gait speed among hospitalized elderly. The differences may be due to the age of participants, their fragility as well as their acute stage, and being hospitalized. The association between anemia and handgrip was in line with previous literature demonstrating that age increasing is related to decreased hemoglobin levels.

In Asian and Iranian culture, particularly in older individuals, women have more responsibility than men in doing housework such as cooking, cleaning, washing dishes, taking care of (grand) children, and their husbands. Therefore, they could maintain muscle strength, especially in their hands. Several previous studies indicated that older men have a higher chance of losing muscle mass with increasing age than older women. This mechanism is not understood completely [35].

Decreases in physiological factors (e.g., insulin-like growth factor-1 and testosterone) and social factors such as work retirement and loss of social roles might dramatically decrease muscle strength in older men, affecting handgrip and their daily activities.

Older adults might have high levels of inflammatory factors due to their underlying chronic diseases. Acute and chronic inflammatory processes decrease Hgb levels and physical function.

At an older age, anemia of chronic diseases is more frequent than age-related anemia. This study found an independent relationship between Hgb levels and physical and cognitive outcomes after adjusting for some chronic diseases related to anemia, such as diabetes, hypertension, and kidney disease.

In some studies, an association between anemia and physical function was still significant after adjusting for underlying diseases $[35,39]$. However, with the increase in the number of these diseases, the severity of the relationship has decreased. Maraldy et al.'s (2006) [40] study was in contrast to this result.

As confirmed in this study, anemic individuals are more inactive and have sedentary lifestyles, which might affect physical performance. Besides, physical activity increases red blood cell production and oxygen-carrying capacity. Older people with a higher level of $\mathrm{Hgb}$ are more physically active; therefore, they have higher muscle mass and strength. One of the most common symptoms of anemia is fatigue. It can significantly limit physical activity, leading to decreased muscle mass and strength [35].

There was a significant difference between the physical activities in anemic and non-anemic participants in the present study. However, according to the adapted model, the relationship between anemia and physical function outcomes, e.g., handgrip, RHGS, usual gait speed, was independent of the effect of physical activity. 
Interestingly, our result shows that the association between $\mathrm{Hgb}$ concentration and usual gait speed was no longer statistically significant in women when participants were stratified by gender, which indicated a gender-related effect on usual gait speed. This result is consistent with previous studies that demonstrated the influences of age and gender on the usual gait speed [41-45]. As studies showed, stride-length and steplength, which are relevant factors for gait speed, were higher in men [46-48]. This result may explain by differences in body composition and size. Notably, gait speed is also affected by culture, lifestyle, and sociodemographics such as education, occupational class, and income. For instance, less educated elderly have lower gait speed and physical activity due to a higher prevalence of chronic underlying diseases, smoking, and obesity [41]. Additionally, studies showed that the level of education is a stronger predictor in men than women. In this study, men were found to have a significantly higher level of education than women.

As this study shows, after considering gender separately, the association between $\mathrm{Hgb}$ concentration and cognitive parameters was no longer significant. This finding indicates the gender differences in cognitive function, consistent with previous studies [49-53]. Additionally, women had a lower cognitive function than men in this study. A possible explanation for this result is differences in the sex hormones changes. As mentioned in the studies, sex hormones have a protective role against cognitive function decline [50, 54, 55]. Furthermore, post-menopausal women have a significant decline in sex hormones, making them more susceptible to cognitive impairment $[56,57]$.. Another possible explanation for gender differences in cognitive function is education level disparities. In this study, women had a lower level of education, and when we consider education into account for the whole participants, the association between $\mathrm{Hgb}$ concentration and semantic memory was no longer significant. This finding supports previous research that confirms the effect of years of formal education on cognitive reserve as a predictor of cognitive impairment in the elderly [58-62]. Moreover, in developing countries such as Iran, women have a lower chance of participation in cognitively demanding jobs, cognitive leisure activities (e.g., reading books, doing word games or puzzles), and intellectual activities due to low education levels and socioeconomic status, which make women more susceptible to cognitive impairment than men [60, 63-66].

Our finding provides a contrast with some previous studies that confirmed the relation between anemia and cognitive impairment [32, 52, 67-71]. These differences might be due to the relatively younger age of participants in this study. Furthermore, it seems that the elderly with older age, less education, and underlying disease are less likely to participate in the studies due to lower physical and cognitive function. Individuals with a lower level of hemoglobin would be unlikely to survive to participate in the studies [13]. Adjusting for multiconfounders might also affect the relationship between $\mathrm{Hgb}$ and cognitive impairment by causing overmatching bias, which reduces the study precision and might obfuscate the relation between variables [46, 72]. Additionally, the cognitive function would likely be affected by culture, education level, and socioeconomic factors more than physical function, which is objective [73, 74].

Regardless of the effect of gender on the association between anemia and cognitive impairment, mechanisms explaining Hgb change, which have a pronounced effect on women than men, are not fully understood [7]. Further longitudinal studies with higher mean age are required to establish the effect of gender and being women on the association between $\mathrm{Hgb}$ concentration and cognitive function.

Our analysis has several strengths; first, a large number of participants represents a sample of a community of older adults of both genders in Iran. Second, a comprehensive measurement of demographic and healthrelated confounders allows us to explore the association between Hgb concentration and physical and cognitive function. Second, previous studies in this field have generally been conducted in high-income countries (HICs) and developed countries. Lower and middle-income countries (LMICs) such as the Middle East countries have a smaller share of these studies. This populationbased study was performed using reliable data and a fully validated protocol. Besides, we examined the effect of anemia on both cognitive and physical function simultaneously as outcome variables in this study, considering various covariates such as sociodemographic factors, lifestyle factors, and illness-related factors. Moreover, the relationship between these variables has still remained controversial despite several studies in this field detailed in Table 5. In this study, we try to clarify this relationship by conducting a study on large community-dwelling elderly. Finally, the physical activity assessment was carried out via objective and questionnaire methods simultaneously; moreover, two different cognitive domains, semantic and late recall, were measured, which are an important component of the cognitive function.

This study has a number of potential limitations; first, the cross-sectional nature of this study could not establish cause-effect relationships between Hgb concentration, cognitive function, and physical function. Second, in this study, only memory and verbal aspects of cognitive function were assessed due to the low educational levels of the participants. In contrast, other cognitive 


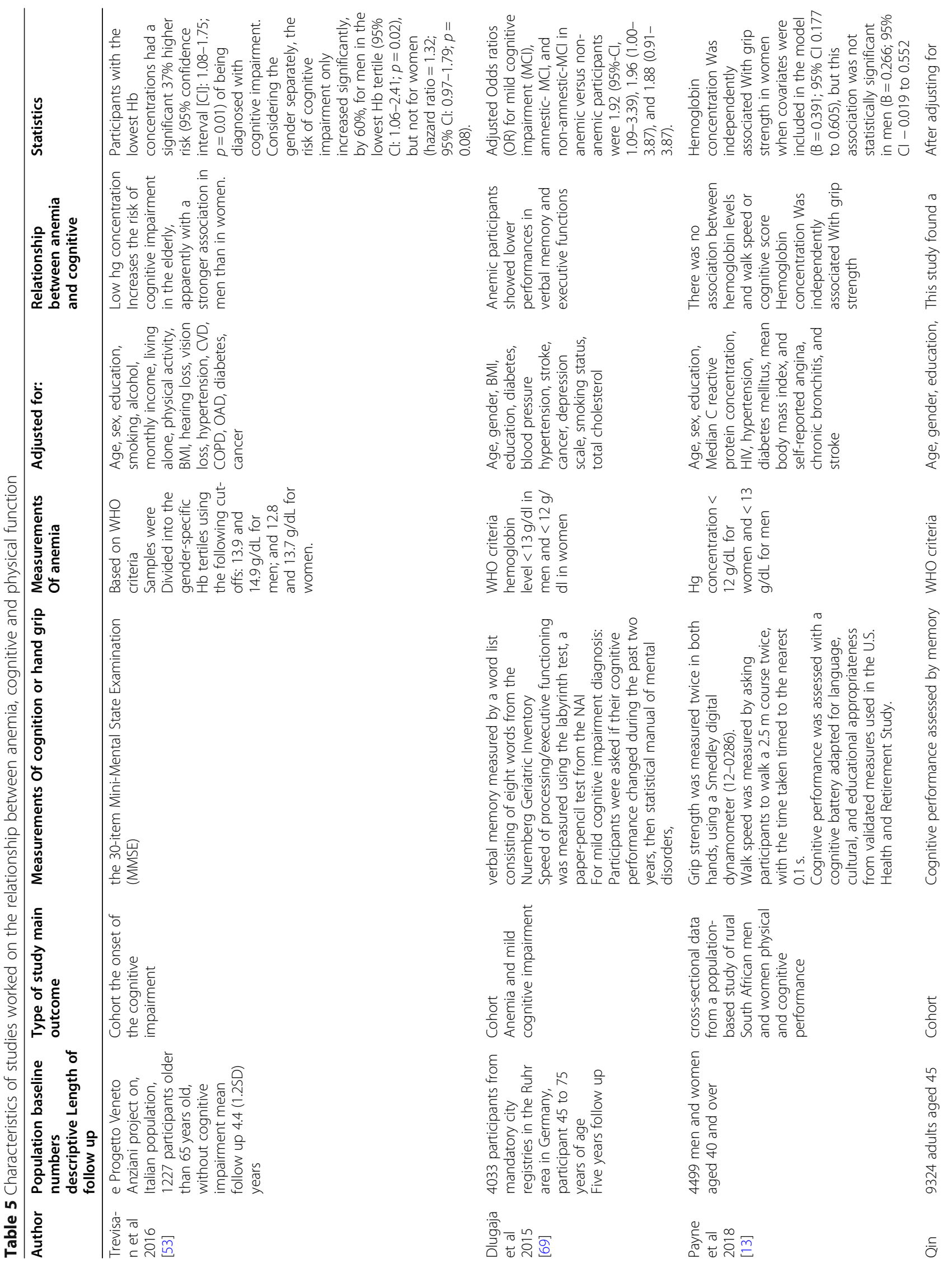




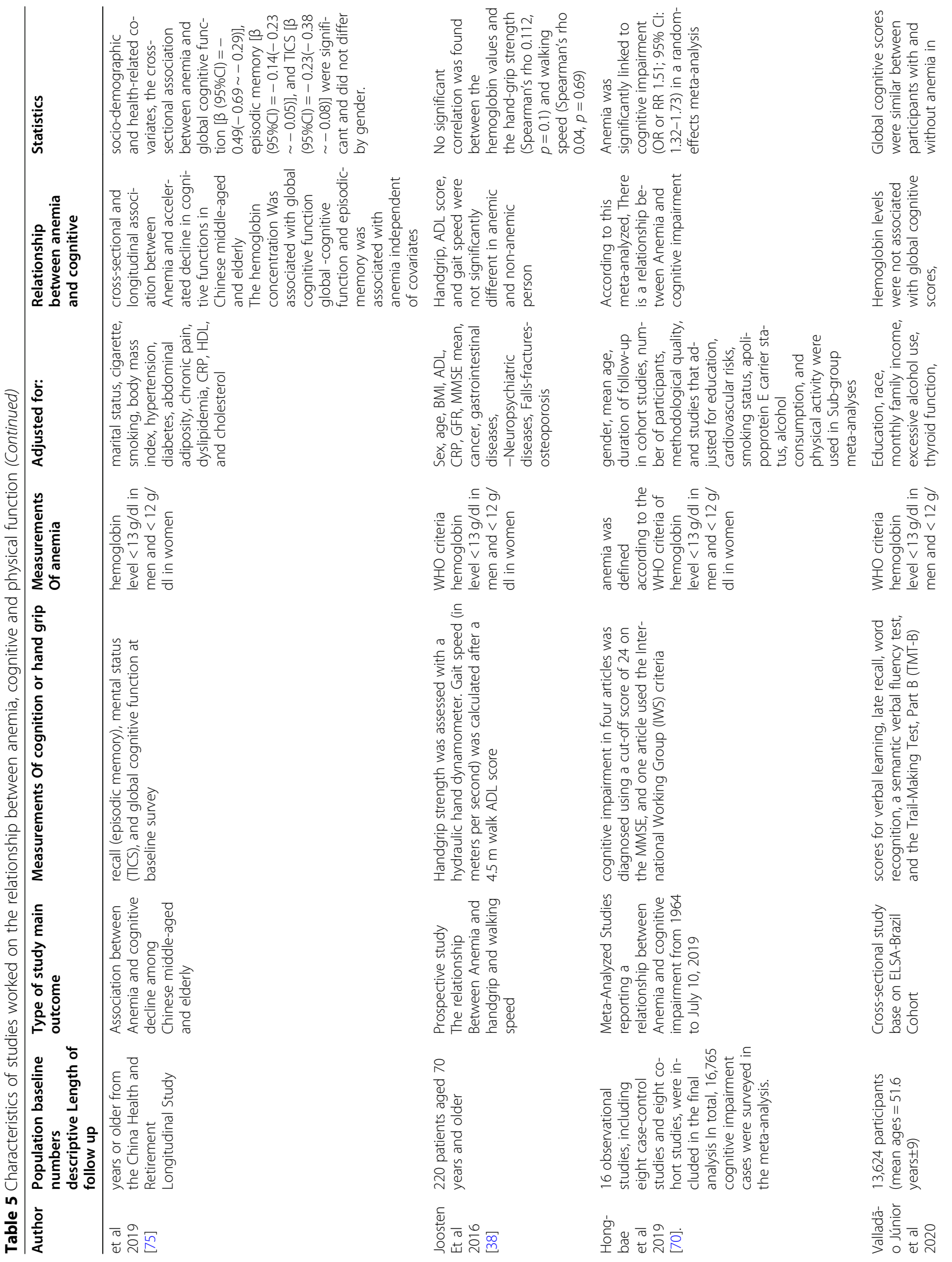




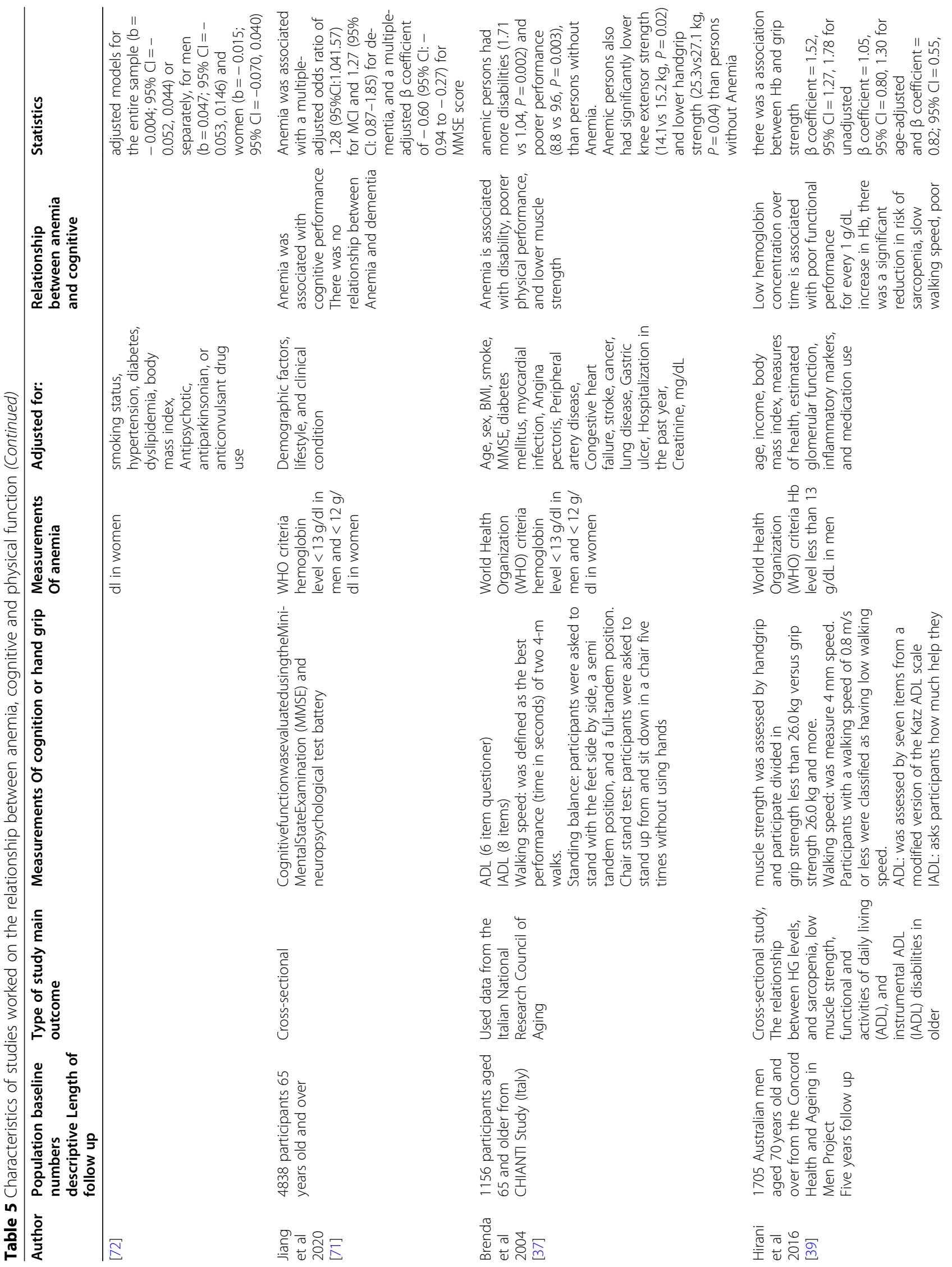




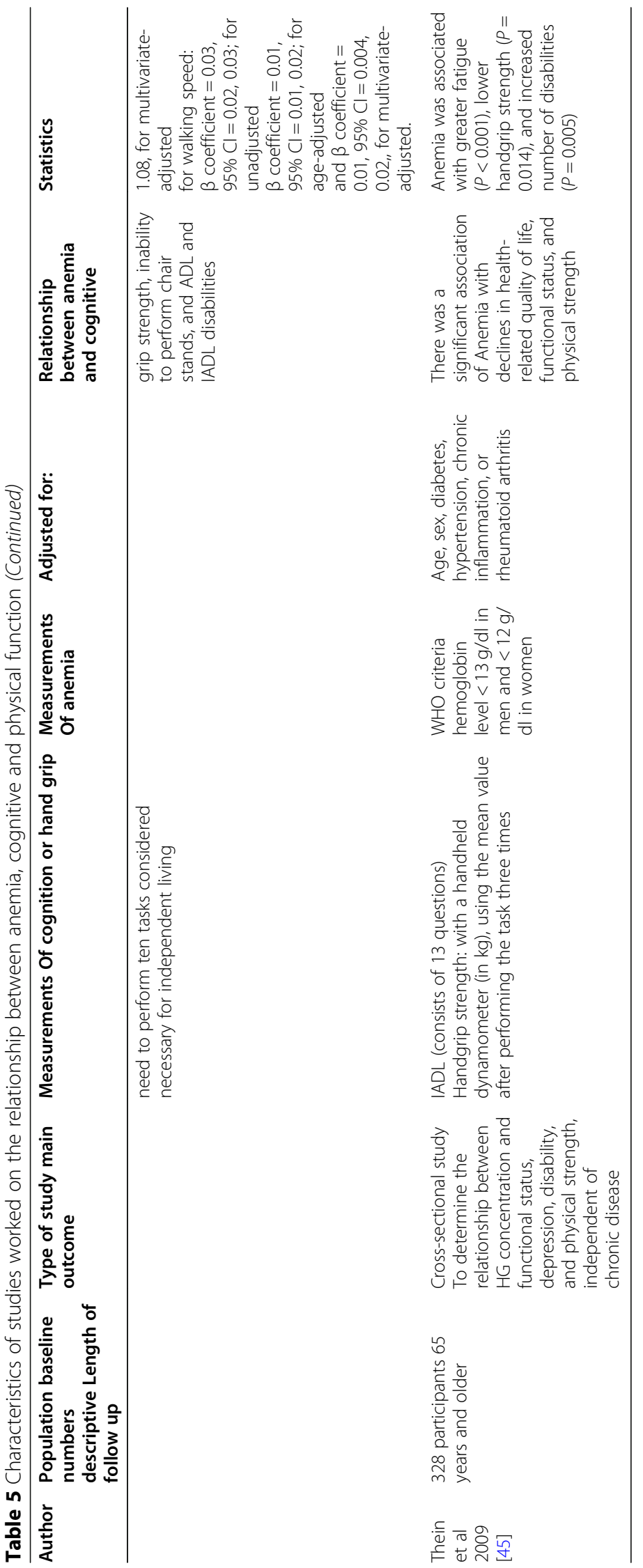


contents, e.g., executive speed, attention, and processing function, which might be affected more than the assessed domains by hemoglobin changes, were not evaluated. Second, due to the population-based nature of the study, brain diseases (e.g., Alzheimer's disease and Parkinson's) were only self-reported, and specific diagnostic tests were not performed to evaluate these diseases. Finally, confounding variables such as inflammatory factors (e.g., C-reactive-protein) and nutritional-status (e.g., albumin) were not assessed in this study.

In conclusion, our study demonstrated that anemia is strongly associated with physical function in the Iranian elderly population, whereas its association with cognitive function was not statistically significant. This research raises the question of whether hemoglobin level correction improves cognitive and physical function. Further longitudinal research is required to investigate the etiology and consequences of anemia in the elderly. Despite uncertain mechanism to explain how anemia affects physical performance and cognitive function, according to the results of this study and previous ones, it seems hemoglobin screening not only might be effective in diagnosing the cognitive function and physical activity decline in the early stage but also might play an important role in preventing these conditions. Moreover, the handgrip strength is one of the evaluation indicators of frailty Syndrome. In this study, its strong relationship with anemia has been confirmed; hence, this finding can strengthen the hypothesis of a relationship between anemia and frailty. We suggest that screening and timely treatment of anemia in the elderly should be considered as a strategy to reduce frailty and improve the rehabilitation process. We believe an effective strategy for controlling anemia in older adults might improve function, quality of life, and even lifespan. Designing an interventional healthcare system for managing anemia plays an essential role in this strategy.

\section{Abbreviations}

BEH Program: Bushehr Elderly Health Program; BMI: The body mass index; CBC: complete blood count; CFT: Category fluency test; Cl: Cognitive impairment; CO: Carbon monoxide; GFR: Glomerular function rate;" Hgb: Hemoglobin; MCH: Mean corpuscular hemoglobin; MCV: Mean corpuscular volume; PLT: Platelets; RBC: Red blood cell count; RDW: Red Cell Distribution Width; RHGS: Relative Handgrip Strength; WBC: White blood cells; WHO: World Health Organization

\section{Acknowledgments}

The authors of this article would like to thank all of the medical research center staff at Bushehr University of Medical Sciences (BUMS) and Tehran University of Medical Sciences (TUMS) for their commitment and cooperation. We would like to express our sincere gratitude to the Clinical Research Development Center of the Persian Gulf Martyrs Hospital and the Persian Gulf Tropical Medicine Research Center of the Persian Gulf Biomedical Sciences Research Institute, affiliated to the Bushehr University of Medical Sciences. We also thank all the participants in this study.

\section{Authors' contributions}

MM and MGH conceived the study and performed data analysis and interpretation. AF and ESH drafted the manuscript and participated in interpretation, study design and conduct and helped draft the manuscript and interpretation. IN, BL, AHD, and AO participated in the study design and interpretation of the findings. All authors reviewed and approved the submitted manuscript.

\section{Funding}

Funding for BEH Program was jointly provided by the Persian Gulf Biomedical Sciences Research Institute affiliated with Bushehr (Port) University of Medical Sciences (BPUMS) and the Endocrinology and Metabolism Research Institute, affiliated with Tehran University of Medical Sciences (TUMS). Researchers from both research centers have contributed to the design and conduct of this research project.

\section{Availability of data and materials}

A large amount of data has been collected for this study. The datasets on which the conclusions of this manuscript rely are available. Interested researchers may access the data via corresponding author $\mathrm{AO}$ (a. ostovar@bpums.ac.ir) or IN (inabipour@gmail.com).

\section{Declarations}

\section{Ethics approval and consent to participate}

The study was approved by the Ethics Committee of Bushehr University of Medical Sciences (ref. No. B-91-14-2). This study was conducted in agreement with the Declaration of Helsinki and Iranian national guidelines for ethics in research. Written informed consent was obtained from all participants prior to study enrolment. Participation was voluntary, and each participant could withdraw consent at any time without any consequence. Data collected were stored in a re-identifiable form by national ID code.

\section{Consent for publication}

Not applicable.

\section{Competing interests}

The authors declare that they have no competing interests.

\section{Author details}

${ }^{1}$ Clinical Research Development Center, The Persian Gulf Martyrs, Bushehr University of Medical Sciences, Bushehr, Iran. ${ }^{2}$ The Persian Gulf Tropical Medicine Research Center, The Persian Gulf Biomedical Sciences Research Institute, Bushehr University of Medical Sciences, Bushehr, Iran. ${ }^{3}$ The Persian Gulf Marine Biotechnology Research Center, The Persian Gulf Biomedical Sciences Research Institute, Bushehr University of Medical Sciences, Bushehr, Iran. ${ }^{4}$ Osteoporosis Research Center, Endocrinology and Metabolism Clinical Sciences Institute, Tehran University of Medical Sciences, Tehran, Iran. ${ }^{5}$ Endocrinology and Metabolism Research Center, Endocrinology and Metabolism Clinical Sciences Institute, Tehran University of Medical Sciences, Tehran, Iran. ${ }^{6}$ Department of Nutrition Science, Bushehr University of Medical Sciences, Bushehr, Iran.

Received: 4 November 2020 Accepted: 11 May 2021

Published online: 24 May 2021

\section{References}

1. Haemoglobin concentrations for the diagnosis of anaemia and assessment of severity [http://www.who.int/iris/handle/10665/85839].

2. Patel KV. Epidemiology of anemia in older adults. In: Seminars in hematology: Elsevier; 2008. p. 210-7.

3. Safavi E, Marzban M, Sadeghmoghadam L, Farhadi A. Iron deficiency anemia in older females: a comparison between community-dwelling individuals and nursing home residents in the Southwest of Iran. Shiraz EMed J. 21(3).

4. Migone de Amicis M, Poggiali E, Motta I, Minonzio F, Fabio G, Hu C, et al. Anemia in elderly hospitalized patients: prevalence and clinical impact. Intern Emerg Med. 2015;10(5):581-6.

5. Chan TC, Yap DY, Shea YF, Luk JK, Chan FH, Chu LW. Prevalence of anemia in Chinese nursing home older adults: implication of age and renal 
impairment. Geriatr Gerontol Int. 2013;13(3):591-6. https://doi.org/10.1111/ j.1447-0594.2012.00942.x.

6. Wolters FJ, Zonneveld HI, Licher S, Cremers LG, Ikram MK, Koudstaal PJ, et al. Hemoglobin and anemia in relation to dementia risk and accompanying changes on brain MRI. Neurology. 2019;93(9):e917-26. https://doi.org/10.1212/WNL.00000000000008003.

7. Shah RC, Wilson RS, Tang Y, Dong X, Murray A, Bennett DA. Relation of hemoglobin to level of cognitive function in older persons. Neuroepidemiology. 2009;32(1):40-6. https://doi.org/10.1159/000170905.

8. Winchester LM, Powell J, Lovestone S, Nevado-Holgado AJ. Red blood cell indices and anaemia as causative factors for cognitive function deficits and for Alzheimer's disease. Genome Med. 2018;10(1):51. https://doi.org/10.1186/ s13073-018-0556-z.

9. Hoffbrand V, Provan D. ABC of clinical haematology. Macrocytic anaemias. BMJ. 1997;314(7078):430-3. https://doi.org/10.1136/bmj.314.7078.430.

10. Selected findings of national population and housing census [https://www.a mar.org.ir/Portals/1/census/2016/Census_2016_Selected_Findings.pdf].

11. Prince M, Comas-Herrera A, Knapp M, Guerchet M, Karagiannidou M. World Alzheimer report 2016: improving healthcare for people living with dementia: coverage, quality and costs now and in the future; 2016.

12. World Alzheimer Report 2019: Attitudes to dementia [https://www.alz.co.uk/ research/world-report-2019].

13. Payne CF, Davies Jl, Gomez-Olive FX, Hands K, Kahn K, Kobayashi LC, et al. Cross-sectional relationship between haemoglobin concentration and measures of physical and cognitive function in an older rural south African population. J Epidemiol Community Health. 2018;72(9):796-802. https://doi. org/10.1136/jech-2018-210449.

14. van der Veen PH, Muller M, Vincken KL, Westerink J, Mali WPTM, van der Graaf $Y$, et al. Hemoglobin, hematocrit, and changes in cerebral blood flow: the second manifestations of ARTerial disease-magnetic resonance study. Neurobiol Aging. 2015;36(3):1417-23. https://doi.org/10.1016/j.neurobiola ging.2014.12.019.

15. Joosten E, Detroyer E, Milisen K. Effect of anaemia on hand grip strength, walking speed, functionality and 1 year mortality in older hospitalized patients. BMC Geriatr. 2016;16(1):153. https://doi.org/10.1186/s12877-016-032 6-y.

16. Myint PK, Owen S, McCarthy K, Pearce L, Moug SJ, Stechman MJ, et al. Is anemia associated with cognitive impairment and delirium among older acute surgical patients? Geriatr Gerontol Int. 2018;18(7):1025-30. https://doi. org/10.1111/ggi.13293.

17. Ostovar A, Nabipour I, Larijani B, Heshmat R, Darabi H, Vahdat K, et al. Bushehr elderly health (BEH) Programme, phase I (cardiovascular system). BMJ Open. 2015;5(12):e009597. https://doi.org/10.1136/bmjopen-2015009597.

18. The survey study of the risk factor of non -communicable disease in Iran. The endcocrynology research center 2016, www.emri.tums.ac.ir/ncdrc.

19. Rezaei M, Rashedi V, Lotfi G, Shirinbayan P, Foroughan M. Psychometric properties of the Persian adaptation of mini-cog test in Iranian older adults. Int J Aging Hum Dev. 2018;86(3):266-80. https://doi.org/10.1177/009141501 7724547.

20. Borson S, Scanlan JM, Chen P, Ganguli M. The mini-cog as a screen for dementia: validation in a population-based sample. J Am Geriatr Soc. 2003; 51(10):1451-4. https://doi.org/10.1046/j.1532-5415.2003.51465.x.

21. Kinuhata S, Takemoto Y, Senda M, Nakai S, Tsumura E, Otoshi T, et al. The 1min animal test as a mental status screening examination in patients with diabetes. Asia Pac Fam Med. 2018;17(1):6. https://doi.org/10.1186/s12930-01 8-0043-0.

22. Roberts HC, Denison HJ, Martin HJ, Patel HP, Syddall H, Cooper C, et al. A review of the measurement of grip strength in clinical and epidemiological studies: towards a standardised approach. Age Ageing. 2011;40(4):423-9. https://doi.org/10.1093/ageing/afr051.

23. Klishadi R, Khosravi A, Famouri F, Sadeghi M, Shirani S. Assessment of physical activity of adolescents in Isfahan. J Shahrekord Univ Med Sci. 2001; 3(2).

24. Aadahl M, Jørgensen T. Validation of a new self-report instrument for measuring physical activity. Med Sci Sports Exerc. 2003;35(7):1196-202. https://doi.org/10.1249/01.MSS.0000074446.02192.14.

25. Alley DE, Shardell MD, Peters KW, McLean RR, Dam T-TL, Kenny AM, et al. Grip strength cutpoints for the identification of clinically relevant weakness. J Gerontol Ser A: Biomed Sci Med Sci. 2014;69(5):559-66. https://doi.org/10.1 093/gerona/glu011.
26. Nathan DM, Genuth S, Lachin J, Cleary P, Crofford O, Davis M, et al. The effect of intensive treatment of diabetes on the development and progression of long-term complications in insulin-dependent diabetes mellitus. N Engl J Med. 1993;329(14):977-86. https://doi.org/10.1056/NEJM1 99309303291401.

27. Intensive blood-glucose control with sulphonylureas or insulin compared with conventional treatment and risk of complications in patients with type 2 diabetes (UKPDS 33). UK Prospective Diabetes Study (UKPDS) Group. Lancet 1998, 352(9131): 837-853.

28. Weykamp C. HbA1c: a review of analytical and clinical aspects. Ann Lab Med. 2013;33(6):393-400. https://doi.org/10.3343/alm.2013.33.6.393.

29. Hosseini SR, Zabihi A, Ebrahimi SH, Amiri SRJ, Kheirkhah F, Bijani A. The prevalence of anemia and its association with depressive symptoms among older adults in north of Iran. J Res Health Sci. 2018;18(4):e00431.

30. Hirani V, Naganathan V, Blyth F, Le Couteur DG, Kelly P, Handelsman DJ, et al. Cross-sectional and longitudinal associations between anemia and frailty in older Australian men: the concord health and aging in men project. J Am Med Dir Assoc. 2015;16(7):614-20. https://doi.org/10.1016/j.ja mda.2015.02.014.

31. Gaskell H, Derry S, Moore RA, McQuay HJ. Prevalence of anaemia in older persons: systematic review. BMC Geriatr. 2008:8(1):1. https://doi.org/10.11 86/1471-2318-8-1.

32. Schneider AL, Jonassaint C, Sharrett AR, Mosley TH, Astor BC, Selvin E, et al. Hemoglobin, anemia, and cognitive function: the atherosclerosis risk in communities study. J Gerontol Ser A: Biomed Sci Med Sci. 2016;71(6):772-9. https://doi.org/10.1093/gerona/glv158.

33. Leifert JA. Anaemia and cigarette smoking. Int J Lab Hematol. 2008;30(3): 177-84. https://doi.org/10.1111/j.1751-553X.2008.01067.x.

34. Grinberg A, Goodwin RD. Prevalence and correlates of hookah use: a nationally representative sample of US adults ages 18-40 years old. Am J Drug Alcohol Abuse. 2016;42(5):567-76. https://doi.org/10.3109/00952990.2 016.1167214.

35. Y-m G, Jung B, Kim K-W, Cho J-H, Ha I-H. Low handgrip strength is closely associated with anemia among adults: a cross-sectional study using Korea National Health and nutrition examination survey (KNHANES). PLoS One. 2020;15(3):e0218058

36. Santos PHS, Carmo ÉA, Carneiro JAO, Nery AA, Casotti CA. Handgrip strength: an effective screening instrument for anemia in the elderly women. Public Health Nurs. 2019;36(2):178-83. https://doi.org/10.1111/ phn.12579.

37. Penninx BW, Pahor M, Cesari M, Corsi AM, Woodman RC, Bandinelli S, et al. Anemia is associated with disability and decreased physical performance and muscle strength in the elderly. J Am Geriatr Soc. 2004;52(5):719-24. https://doi.org/10.1111/j.1532-5415.2004.52208.x.

38. Joosten E, Detroyer E, Milisen K. Effect of anaemia on hand grip strength, walking speed, functionality and 1 year mortality in older hospitalized patients. BMC Geriatr. 2016;16(1):1-6.

39. Hirani V, Naganathan V, Blyth F, Le Couteur DG, Seibel MJ, Waite LM, et al. Low hemoglobin concentrations are associated with sarcopenia, physical performance, and disability in older Australian men in cross-sectional and longitudinal analysis: the Concord Health and Ageing in Men project. J Gerontol Ser A: Biomed Sci Med Sci. 2016;71(12):1667-75. https://doi.org/1 0.1093/gerona/glw055

40. Maraldi C, Ble A, Zuliani G, Guralnik JM, Mussi C, Fellin R, et al. Association between anemia and physical disability in older patients: role of comorbidity. Aging Clin Exp Res. 2006;18(6):485-92. https://doi.org/10.1007/ BF03324848.

41. Brunner E, Shipley M, Spencer V, Kivimaki M, Chandola T, Gimeno D, et al. Social inequality in walking speed in early old age in the Whitehall II study. J Gerontol Ser A: Biomed Sci Med Sci. 2009;64(10):1082-9.

42. Welmer A-K, Kåreholt I, Rydwik E, Angleman S, Wang H-X. Education-related differences in physical performance after age 60: a cross-sectional study assessing variation by age, gender and occupation. BMC Public Health. 2013;13(1):641. https://doi.org/10.1186/1471-2458-13-641.

43. Plouvier S, Carton M, Cyr D, Sabia S, Leclerc A, Zins M, et al. Socioeconomic disparities in gait speed and associated characteristics in early old age. BMC Musculoskelet Disord. 2016;17(1):178. https://doi.org/10.1186/s12891-016-1033-8.

44. Layman AJ, Li C, Simonsick E, Ferrucci L, Carey JP, Agrawal Y. Association between saccular function and gait speed: data from the Baltimore longitudinal study of aging. Otol Neurotol. 2015;36(2):260-6. https://doi. org/10.1097/MAO.0000000000000544. 
45. Thein M, Ershler WB, Artz AS, Tecson J, Robinson BE, Rothstein G, et al. Diminished quality of life and physical function in community-dwelling elderly with anemia. Medicine. 2009;88(2):107-14. https://doi.org/10.1097/ MD.0b013e31819d89d5.

46. Bloom MS, Schisterman EF, Hediger ML. The use and misuse of matching in case-control studies: the example of polycystic ovary syndrome. Fertil Steril. 2007;88(3):707-10. https://doi.org/10.1016/j.fertnstert.2006.11.125.

47. Jung HW, Jang IY, Lee CK, Yu SS, Hwang JK, Jeon C, et al. Usual gait speed is associated with frailty status, institutionalization, and mortality in community-dwelling rural older adults: a longitudinal analysis of the aging study of Pyeongchang rural area. Clin Interv Aging. 2018;13:1079-89. https://doi.org/10.2147/CIA.S166863

48. Bohannon RW, Wang Y-C. Four-meter gait speed: normative values and reliability determined for adults participating in the nih toolbox study. Arch Phys Med Rehabil. 2019;100(3):509-13. https://doi.org/10.1016/j.apmr.2018. 06.031.

49. Li R, Singh M. Sex differences in cognitive impairment and Alzheimer's disease. Front Neuroendocrinol. 2014;35(3):385-403. https://doi.org/10.1016/ j.yfrne.2014.01.002

50. Asthana S, Baker L, Craft S, Stanczyk F, Veith R, Raskind M, et al. High-dose estradiol improves cognition for women with AD: results of a randomized study. Neurology. 2001;57(4):605-12. https://doi.org/10.1212/WNL.57.4.605.

51. Geerlings MI, Strozyk D, Masaki K, Remaley AT, Petrovitch H, Ross GW, et al. Endogenous sex hormones, cognitive decline, and future dementia in old men. Ann Neurol. 2006;60(3):346-55. https://doi.org/10.1002/ana.20918.

52. Qin T, Yan M, Fu Z, Song Y, Lu W, Yin P. Association between anemia and cognitive decline among Chinese middle-aged and elderly: evidence from the China health and retirement longitudinal study. BMC Geriatr. 2019;19(1): 305. https://doi.org/10.1186/s12877-019-1308-7.

53. Trevisan C, Veronese N, Bolzetta F, De Rui M, Maggi S, Zambon S, et al. Low hemoglobin levels and the onset of cognitive impairment in older people: the PRO. VA study. Rejuvenation Res. 2016;19(6):447-55. https://doi.org/10.1 089/rej.2015.1768.

54. Sherwin BB. Estrogen and cognitive functioning in women. Endocr Rev. 2003;24(2):133-51. https://doi.org/10.1210/er.2001-0016.

55. Cherrier M, Matsumoto A, Amory J, Asthana S, Bremner W, Peskind E, et al. Testosterone improves spatial memory in men with Alzheimer disease and mild cognitive impairment. Neurology. 2005;64(12):2063-8. https://doi.org/1 0.1212/01.WNL.0000165995.98986.F1.

56. Xing Y, Wei C, Chu C, Zhou A, Li F, Wu L, et al. Stage-specific gender differences in cognitive and neuropsychiatric manifestations of vascular dementia. Am J Alzheimers Dis Other Dement. 2012;27(6):433-8.

57. Barron AM, Pike CJ. Sex hormones, aging, and Alzheimer's disease. Front Biosci. 2012:4:976.

58. Feinkohl I, Winterer G, Spies CD, Pischon T. Cognitive reserve and the risk of postoperative cognitive dysfunction: a systematic review and meta-analysis. Dtsch Arztebl Int. 2017;114(7):110-7. https://doi.org/10.3238/arztebl.2017.0110

59. Lee S, Buring JE, Cook NR, Grodstein F. The relation of education and income to cognitive function among professional women. Neuroepidemiology. 2006;26(2):93-101. https://doi.org/10.1159/000090254

60. Ihle A, Gouveia E, Gouveia B, Freitas D, Jurema J, Kliegel M. The relation of education, occupation, and cognitive activity to minimental state in old age: the role of frailty. Int Psychogeriatr. 2017;29(9):1469-74. https://doi. org/10.1017/S1041610217000795.

61. Ramakrishnan S, Mekala S, Mamidipudi A, Yareeda S, Mridula R, Bak TH, et al. Comparative effects of education and bilingualism on the onset of mild cognitive impairment. Dement Geriatr Cogn Disord. 2017:44(3-4):222-31. https://doi.org/10.1159/000479791.

62. Wada M, Noda Y, Shinagawa S, Chung JK, Sawada K, Ogyu K, et al. Effect of education on Alzheimer's disease-related neuroimaging biomarkers in healthy controls, and participants with mild cognitive impairment and Alzheimer's disease: a cross-sectional study. J Alzheimers Dis. 2018;63(2): 861-9. https://doi.org/10.3233/JAD-171168.

63. Sumowski J, Wylie G, Gonnella A, Chiaravalloti N, Deluca J. Premorbid cognitive leisure independently contributes to cognitive reserve in multiple sclerosis. Neurology. 2010;75(16):1428-31. https://doi.org/10.1212/WNL. 0b013e3181f881a6.

64. Yang $L$, Jin $X, Y a n J$, Jin $Y, X u S, X u Y$, et al. Comparison of prevalence and associated risk factors of cognitive function status among elderly between nursing homes and common communities of China: A STROBE-compliant observational study. Medicine. 2019;98(49).
65. Dinsa GD, Goryakin Y, Fumagalli E, Suhrcke M. Obesity and socioeconomic status in developing countries: a systematic review. Obes Rev. 2012;13(11): 1067-79. https://doi.org/10.1111/j.1467-789X.2012.01017.x.

66. Iyer GK, Alladi S, Bak TH, Shailaja M, Mamidipudi A, Rajan A, et al. Dementia in developing countries: does education play the same role in India as in the west? Dement Neuropsychol. 2014;8(2):132-40. https://doi.org/10.1590/ S1980-57642014DN82000008.

67. Shah R, Buchman A, Wilson R, Leurgans S, Bennett D. Hemoglobin level in older persons and incident Alzheimer disease: prospective cohort analysis. Neurology. 2011;77(3):219-26. https://doi.org/10.1212/WNL.0b013e31822 5 aaa9.

68. Deal JA, Carlson MC, Xue QL, Fried LP, Chaves PH. Anemia and 9-year domain-specific cognitive decline in community-dwelling older women: the Women's health and aging study II. J Am Geriatr Soc. 2009;57(9):1604-11. https://doi.org/10.1111/j.1532-5415.2009.02400.x.

69. Dlugaj M, Winkler A, Weimar C, Duerig J, Broecker-Preuss M, Dragano N, et al. Anemia and mild cognitive impairment in the German general population. J Alzheimers Dis. 2016;49(4):1031-42. https://doi.org/10.3233/JA D-150434.

70. Kim H-B, Park B, Shim J-Y. Anemia in association with cognitive impairment: a systematic review and meta-analysis. J Alzheimers Dis. 2019;72(3):803-14. https://doi.org/10.3233/JAD-190521.

71. Jiang Z, Han X, Wang Y, Hou T, Cong L, Tang S, et al. Anemia, mild cognitive impairment, and dementia among rural-dwelling older adults: a population-based study. In: 2020 Alzheimer's Association International Conference; 2020. ALZ

72. Valladão Júnior JBR, Suemoto CK, Goulart AC, Schmidt MI, Passos VM, Barreto SM, et al. Anemia and cognitive performance in the ELSA-Brasil cohort baseline. J Neuropsychiatry Clin Neurosci. 2020;32(3):227-34. https:// doi.org/10.1176/appi.neuropsych.19040088.

73. Muggleton NG, Banissy MJ. Culture and cognition. Cogn Neurosci. 2014;5(1): 1-2. https://doi.org/10.1080/17588928.2014.885781.

74. Park DC, Nisbett R, Hedden T. Aging, culture, and cognition. J Gerontol Ser B Psychol Sci Soc Sci. 1999;54(2):P75-84.

75. Qin T, Yan M, Fu Z, Song Y, Lu W, Yin P. Association between anemia and cognitive decline among Chinese middle-aged and elderly: evidence from the China health and retirement longitudinal study. BMC Geriatr. 2019;19(1): $1-13$.

\section{Publisher's Note}

Springer Nature remains neutral with regard to jurisdictional claims in published maps and institutional affiliations.

Ready to submit your research? Choose BMC and benefit from

- fast, convenient online submission

- thorough peer review by experienced researchers in your field

- rapid publication on acceptance

- support for research data, including large and complex data types

- gold Open Access which fosters wider collaboration and increased citations

- maximum visibility for your research: over $100 \mathrm{M}$ website views per year

At $\mathrm{BMC}$, research is always in progress.

Learn more biomedcentral.com/submissions 